\title{
THE ORIGIN OF NUMBER AND THE ORIGIN OF GEOMETRY: ISSUES RAISED AND CONCEPTIONS ASSUMED BY EDMUND HUSSERL
}

\author{
A ORIGEM DO NÚMERO E A ORIGEM DA GEOMETRIA: QUESTÕES \\ LEVANTADAS E CONCEPÇÕES ASSUMIDAS POR EDMUND HUSSERL
}

\author{
Maria Aparecida Viggiani Bicudo ${ }^{1}$
}

\begin{abstract}
The objective of this article is to present the concept of origin, as presented in Husserl's initial studies, and the same concept as it appears in his final work. The views he assumed in the different phases of his life are addressed: in Halle, when he follows Brentanian psychology to support the origin of number; in Göttingen, where he remains until 1916, when his thinking about reduction matures; and the final stage in Freiburg. The article presents ways through which he understood and explained the origin of number, considered in the first phase and his first studies as central for the clarification of the fundaments of mathematics. It further presents how he explained the origin of geometry, under the dimension of the lifeworld, as well as his conception of knowledge and reality, already understood in the 1930s and throughout the years nearing his death as life-world.
\end{abstract}

Keywords: Phenomenology; Origin of number; Origin of geometry; Crisis of modern sciences; Historical a priori.

Resumo: A proposta, neste artigo, é apresentar a concepção de origem, com a qual Husserl trabalha em seus estudos iniciais, e a de origem como aparece nos seus trabalhos finais. São abordadas as visões assumidas por esse autor em suas diferentes fases de vida: em Halle, fase em que segue a psicologia brentania para fundamentar a origem do número; em Göttingen, onde permanece até 1916 e fase em que seu pensamento sobre a redução amadure; fase final, em que permanece em Friburg. São apresentados os modos pelos quais entende e expõe a origem do número, tido nessa sua primeira fase e nos primeiros estudos como fulcral para esclarecer os fundamentos da matemática. São apresentados os modos pelos quais expõe a origem da geometria, vista na dimensão do Life-World, apresentando sua concepção de conhecimento e de realidade, entendida já na década de 1930 e nos anos próximos ao seu falecimento, como mundo-vida.

Palavras-chave: Fenomenologia; Origem do número; Origem da geometria; Crise das ciências modernas; Historical a priori.

\section{Presenting the objective}

As I began studying Husserl's work, I wondered why he insisted on understanding the origin and how he developed his investigations over nearly six decades. This is a theme that worried him from the very beginning of his academic life. In his doctoral work, Philosophy of Arithmetic, presented in 1887 and published in 1891, his research focused on numbers. At the end of his life, in 1926 he wrote The Origin of Geometry, published

\footnotetext{
${ }^{1}$ Professor of the Graduate program in Mathematics Education, São Paulo State University (UNESP), Rio Claro, São Paulo, Brazil. Researcher at Conselho Nacional de Pesquisa - CNPq. President of the Society of Qualitative Investigation-SE\&PQ. E-mail: mariabicudo@gmail.com
} 
by Eugene Fink, in 1939. Clarifying origin in Husserl's work is the inspiration behind this little essay.

The objective of this article is to present the concept of origin, with which Husserl worked in his initial studies, and of origin as it appears in his final work. As I understand it, they maintain a common core, evidenced by the root of the notion of this concept ${ }^{2}$, although the historical-cultural context in which Husserl lived changed throughout his life, as well as his conceptions of philosophy and research. It was initially understood as psychological analysis and, as his studies developed, understood as eidetic phenomenology and transcendental phenomenology.

In the early 1880s, Husserl was a student in Vienna. While studying functions theory, during the classes he took with Weierstrass, as indicated in Ms. BII23 p. 8th, cited by Prada (1986, p. 53), his attention became specifically focused on the issue of the radical foundation of mathematics. His driving motto was already based on philosophy because, at that time, he already viewed it as having the task of clarifying basic concepts of science.

At that time, his investigative interest turned to mathematics, the science with which he worked, and his attention was directed to arithmetic. He was attuned to the common positions of important mathematicians, such as: Weierstrass ${ }^{3}$, Dedekind ${ }^{4}$, Kronecker $^{5}$ and Cantor 6 .

\footnotetext{
${ }^{2}$ This core lies in the intuition which immediately gives the subject what is understood in perception.

${ }^{3}$ Karl Theodor Wilhelm Weierstrass (1815 - 1897) made advances in the field of calculus of variations, using the apparatus of analysis that he helped to develop. Weierstrass developed Cauchy's epsilon-delta method, which established the current language of analysis. Without diminishing the importance of calculus of variations; this exacted a much more significant influence than his work on this topic. The importance of his work comes from the fact that the more general concept of real number has until then only been perceived intuitively; its existence in the sphere of mathematics was only ensured by considerations of a geometric and algebraic.From the beginning of the 19th century, a growing concern arose in placing Analysis on solid arithmetic bases. In the growing climate of discussions in the academic mathematical environment, it became evident that the lack of a theory of real numbers that could provide a more correct or at least complete basis and could made the (technical) demonstrations of certain results incorrect. It follows from this, that the arithmetization of Analysis had shown then a promising theory of the real line on purely arithmetic foundations.

${ }^{4}$ Julius Wilhelm Richard Dedekind (1831 - 1916) developed a major redefinition of irrational numbers in terms of arithmetic concepts. Although not fully recognized in his lifetime, his treatment of the ideas of the infinite and of what constitutes a real number continues to influence modern mathematics.

${ }^{5}$ Leopold Kronecker (1823-1891 He contributed significantly to Algebra although his ideas at the time were considered metaphysical. He insisted on the idea that Arithmetic and Analysis should be based on whole numbers which he considered as having God-given meaning. He rejected the construction of real numbers because it could not be done by finite processes. He approved the universal arithmetization of Analysis but did not admit the existence of irrational numbers; fought for their extinction, a point of contention with Cantor.

${ }^{6}$ Georg Ferdinand Ludwig Philipp Cantor (03-03-1845 - 06-01-1918) He proved that infinite sets (do not have the same potency or the same greatness. He distinguishes between countable sets and uncountable
} 
Husserl interest in investigating the origin of numbers comes from Weierstrass. He was a mathematician living through the movement that had been taking place from the beginning of the 19th century that displayed a growing concern about placing Analysis on solid arithmetic bases. In the growing climate of discussions in the academic mathematical environment, the lack of a theory of real numbers became evident, and it was understood that such theory could provide a more correct or at least complete basis for technical demonstrations. Thus, that the arithmetization of Analysis was shown as a promising theory of the real line on purely arithmetic foundations.

Following this objective, Husserl pursued the task of investigating philosophically the fundaments of arithmetic, seeking to clarify the "original bases" of the edifice of mathematics ${ }^{7}$. At the beginning of his academic life, he had not yet conducted a phenomenology of the sciences. By that time, he merely took the crisis of the fundaments of mathematics that was being contemplated, and advanced in search for clarification of the basic concepts of that science. So, he worked with the origin of number, looking into the psychological acts which originate it, as he then understood it. He performed a transcendental phenomenological analysis regarding the sciences, in general, in the works he presented from around 1930 until his death in 1937, published in the Crises of European Sciences and Transcendental Phenomenology (HUSSERL, 1970) ${ }^{8}$. This analysis is important for the comprehension of what was presented in The Origin of Geometry (HUSSERL, 1970).

In 1882 Husserl presented his doctoral thesis Beiträge zur Theorie der Variationsrechnung whose objective, according to Prada (1986, p. 53), was simplifying the method of proof in the calculation of variations so as to reduce the problems regarding differential equations. In his research, he realized that the very concept of number was taken as a given, without being questioned: What is a number? How is it constituted?

This matter absorbs him to such an extent that it comprises his post-doctoral thesis (Habilitationsschrift), entitled Concerning the Concept of Number: Psychological

\footnotetext{
sets. He proved, also, that Rational Numbers - Q are countable and that Real Numbers IR are continuous, that is, IR are bigger than Q.

${ }^{7}$ As I understand from the context of Husserl's work, mathematics is viewed as a Western science founded in the theorizing thought of the Greeks.

${ }^{8}$ This translation to English of Logische Untersuchungen - LU was conducted by David Kerr, who was, at the time of the translations, assistant professor of philosophy at Yale University.
} 
Analysis (Über den Begriff de Zahal), printed in 1887 and published 1891 under the title Philosophy of Arithmetic- PA (Philosofie der Aritmetik) 9

In that work Husserl focused on three main issues: 1. What is number itself? 2. In what kind of cognitive act is number itself truly present to our minds? (HUSSERL, 2003, p. ix) and, in Husserl's words,

\begin{abstract}
But how can one speak of concepts which one does not genuinely [eigentlich] have? And how is it not absurd that upon such concepts the most secure of all sciences, arithmetic, should be grounded? The answer is: Even if we do not have the concept given in the authentic [eigentlicher] manner, we still do have it given - in the symbolic manner. The discussion of this essential distinction, and the psychological analysis of the symbolic number representations, are to form the task of the following chapters (HUSSERL, 2003, p. 203).
\end{abstract}

As stated in the title of the work itself, it is a psychological analysis. This title already exposed the connection of Husserl with Weierstrass, a mathematician, and Brentano, an important psychologist in German academic circles of that time, for assuming descriptive psychology, and whose classes he attended between 1884 and 1886 . In that aspect he differed from the prevailing school of psychologists of his time who worked with genetic psychology ${ }^{10}$. He studied with Brentano, who exerted great influence on him, especially his early work.

\title{
2 The psychological analysis of number and the theoretical impediments detected
}

Husserl inherited from Brentano the method for working with the description of experiences and the notion of intentionality. Both experience and intentionality, persist throughout the development of his work, however, they were modified in the different phases of his life. These can be understood as those in which he worked more predominantly with Brentanian psychology, in Halle; the phase when he worked in Göttingen, when he developed the bases of eidetic phenomenology and performed a metaunderstanding of the work carried out around 1910, aiming to understand the method that was used in the research developed, culminating, in 1913, with the publication of Ideas General introduction to pure phenomenology (1972), which inaugurated his third phase,

\footnotetext{
9 This article is based on a translation to the English language by Dallas Willard, from the School of Philosophy, University of Southern California, Los Angeles, edited by Springer Science+Business Media, B.V., 2003. This is a publication of "Edmund Husserl - Collected works; editor Rodof Bernet, volume X. ${ }^{10}$ Genetic Psychology, as Brentano says, has the purpose of explaining psychology by formulation of laws of coexistence and succession; the method where these methods are discovered is that of natural sciences. So, it follows an inductive procedure to stablish general laws as "general facts" (De Boer, 1978, p. 52). Descriptive psychology describes the psychical phenomena to explain them. The main point is that he assumes those phenomena as intentional.
} 
when he goes on to explain and assume transcendental phenomenology, transferring to the University of Freiburg, where he remained from 1916 until the end of his days.

In the period he was in Halle he worked with the origin of numbers and started to shift towards self-criticism, heeding the criticism of colleagues, especially Frege and, deepening rigorous philosophical thinking, dedicating himself to exposing insights on ways to overcome the obstacles detected and visualizing possibilities not for working with psychical phenomena, but with the eidos or essence (Wesen) ${ }^{11}$. This indicates his theoretical shift in relation to aspects of Brentano's descriptive psychology. This is because "The essence $(\text { Eidos })^{12}$ is an object of a new type. Just as the datum of individual or empirical intuition is an individual object, so the datum of the essential intuition is a pure essence" (HUSSERL, 1972, p 49). And further affirmed "Thus the essential insight is intuition, and if it is insight in the pregnant sense of the term, and not a mere, and possibly vague, representation, it is a primordial dator" (HUSSERL, 1972, p. 49).

Next, I will focus on Brentano's vision, to explain the important notions that are revisited by Husserl, initially following them, and subsequently, making significant theoretical modifications.

Brentano sees reality as being divided into physical phenomena and psychical phenomena. The former refers to the observable reality in its empiricism. Psychical phenomena are characterized by their properties, among which the most important is intentionality. Thus, he assumes that intentionality is in the external reality because it is a property of psychical phenomena, which belong to reality.

Intentionality is a characteristic that focuses on the difference between genetic psychology, predominant at the time, and descriptive psychology, assumed by Brentano. This concept is derived from Middle Ages scholasticism. According to De Boer (1978), the scholastics of that period characterize psychical phenomenon as intentional and immanent to the mind. That is, it is an intentional and mental phenomenon, thus, separated from external reality. The being is within the sphere of consciousness, where the cognitive process that operates with images of external objects and representations of species occurs. For example, red is the color present in the external object and the intentional red

\footnotetext{
${ }^{11}$ According to Ales Bello (2000, p. 37), he understands that the use he used to make of the word "idea" in Logische Untersuchungen - LU, could have been equivocal and confused with the Kantian concept of idea, thus he prefers to substitute it by Wesen, a German word which means essence, or eidos, a foreign, Greek word.

${ }^{12}$ It is important to reiterate that his conception of essence or eidos as assumed by Husserl differs from that explained in the theory of Ideas of Plato.
} 
color that represents it. It is represented in the mind. Cognitive acts take place in the mind and what is presented in the mind is considered reality. It must be highlighted that, according to this view, intentionality remains within the scope of consciousness.

When understanding reality divided into physical and psychical phenomena, Brentano makes an important change regarding the worldview of scholastics, since even psychical phenomena are not circumscribed to the mind. This aspect concerns ontology. As for intentionality, which also affects epistemology, he views it as an act of pointing to or addressing a phenomenon, both physical and psychical. This is an understanding of intentionality as "intent", which is not confined within consciousness, but connects it with the outside world ${ }^{13}$. This way of understanding intentionality remains in Brentano's and Husserl's philosophy, albeit with modifications, resulting from the development of the latter.

In the Philosophy of Arithmetic Husserl follows Brentano. Thus, he seeks the origin of number in psychological acts, which, as we have seen, belong to the phenomena of reality. Following his master, he describes internal psychological experiences. And, like him, Husserl believes that the task of philosophy is to clarify the concepts of science. Thus, he seeks to clarify the origins of numbers within the scope of arithmetic which includes natural numbers or whole numbers. Thus, numbers (seen either as natural or whole numbers) are the foundation of the theory of real numbers with its continuity property. Thus, arithmetic is the base for the construction of reals which ground mathematics. When applying himself to the study of the origin of number, Husserl tackled a central issue for constituting mathematics, and, faithful to his views regarding the task of philosophy, as previously stated, sought to clarify an important concept for that science.

In addition to the issue of the origin of number, he also sought to clarify the symbolic methods present in the modes of operation in this area. For him, the analysis of the whole number "[...] by no means merely serves arithmetical purposes. The correlated concepts of unity, multiplicity and numbers are concepts fundamental to human knowledge on the whole, and, as such, they lay claim to a distinctive philosophical intent [...]" (HUSSERL, 2003, p. 14).

\footnotetext{
${ }^{13}$ When using "pointing to" Brentano did not mean point to ends, under the perspective of Teleology, but indicates physical phenomena which lies within the reality that is external to the human mind, but in a way that is close to the acts being conducted.
} 
Psychology is important for the classification of such concepts, as it encompasses the interests that concern the clarification of arithmetic, as well as the psychical acts which form the basis of the origin of numbers

In the analysis that he develops in $P A$, Husserl states that concepts in the context of mathematical theories are not important, although mathematicians always seek to define all the terms with which they work. The concept of number, for example, is sometimes defined by way of the concept of equivalence. But this is an artificial construction whereby something familiar is obscured by something remote and strange. Euclid, for example, defines "the number is a multiplicity of units" (HUSSERL, 2003, p. 15). This definition itself leads to a successive return to it, as it does not explain what unit or multiplicity are. Then, one might question how to understand number, while avoiding this circularity in the exposition of such understanding, thus avoiding the tautological character of the concepts, or the lack of meaning of definitions given by mathematicians, or even the recourses which they use to resolve the exposition; resources that cause other difficulties either of mathematical nature or otherwise.

In $P A$ he exposed extensive studies he conducted on ways mathematicians present the concepts of number. As an example, to clarify the depth of his studies, I list some flashes of what he presented regarding F.A. Lang in PA, page 35, and others. Following Kant's idea who, more generally, Lang stresses "the temporal 'form of intuition as the foundation of the concept of number', which came from the well-known Aristotle's conception Time is the number of movement in respect to earlier or later" Husserl (2003, p. 33). Husserl stated that Lang supposes "that everything that time achieves for Kant can be derived with far greater simplicity and certainty from the representation of space" (HUSSERL, 2003, p. 35).

On pages 36 and 37 of $P A$ Husserl stated "the synthesis upon which the concept of number is founded (the collective combination in our language) is, for him (Lang), a synthesis of spatial intuitions. In quite the same manner as geometry, accordingly, arithmetic is supposed to rest upon spatial intuition" (HUSSERL, 2003, p. 37) ${ }^{14}$. He argued that Lang reduces mathematical thinking and logic to spatial intuition. By acting this way, the representation of space becomes, in his view, a psychological prerequisite for the origin of the concept of number. Therefore, instead of clarifying such fundaments, it obscures them.

${ }^{14}$ This issue will be further explained in this article when addressing the issue of the origin of geometry. 
Husserl's intention is to explain the origin of number, without resorting to explanations which are external to the very actions it actualizes. He saw such concepts as originating in intuition, which realizes acts that encompass the phenomenon in point through intentionality. Wherefore they originate from the intended objects, while "engulfed or encircled" by intuition or perception.

He defines number as "a specification of the concept of plurality, and he believes he has found the origin of the concept of plurality in the inner perception of collecting acts" (DE BOER, 1978, p. 64). When given a multiplicity, the question "how many?" is posed and the answer is given indicating the appropriate number. In Philosophy of Arithmetic, Husserl expresses the concrete bases of the abstraction from the concrete phenomena that form the foundations of multiplicity, and thus, of number. He distinguishes the authentically represented multiplicities from those represented symbolically. The former concerns the psychological characterization of the abstraction.

The abstraction is carried out in the perception of a collection of objects from which special contents are separated, because attention is focused on them, from other objects that do not capture the attention. In this phase of Husserl's professional life, considerably reliant on Brentano's psychology, abstraction is derived from the attention present in the perception act. Abstraction creates a separation in the aspects of content of the object that are present in perception. This can result in both negative and positive aspects. From a negative standpoint, this leads to a distancing from something, or results in aspects being ignored. From a positive standpoint something can be particularly emphasized.

Husserl believes that abstraction is at the core of the formation of concept, which cannot be seen without a concrete intuition. He states, "Hence, even when we represent the general concept of multiplicity, we always have in consciousness the intuition of some concrete multiplicity by means of which we abstract the general concept" (HUSSERL, 2003, p. 83) and he argues that if it were not so, we would fall into the nominalism that sees in the concept only the signs, but not the meaning of what it is said. If it is so, then, what is the basis of the general concepts?

This question comes up especially in the case of a priori concepts, which form the basis of laws 'grounded purely in concepts. Yet they are the only general concepts in the full sense of the world, for the empirical concepts that rest on induction are not universal but are limited in their extension to the perceived instances and contingent state of research. According to Husserl, the general concept is abstracted from that which a several objects have in common. Abstraction is an act of attention in which we disregard the difference and 
focus exclusively on similarities. That which multiple things have in common, the fundamentum-in-re of the general concept (DE BOER, 1978, p. 235).

However, the general concept is not formed directly from the apprehension and respective collection of content. As the interest that affects the act of isolating characteristics is not directed to the content of phenomena, but exclusively to the linkage among content, intentionally separated and perceived in thought.

The grasp of contents, and the collection of them, is of course the precondition of the abstraction. But in that abstraction the isolating interest is not directed upon the contents, but rather exclusively upon their linkage in thought - and that linkage is all that is intended (HUSSERL, 2003, p. 83).

Thus, the concept of oneness derives from the abstraction of content perceived in objects, separated from the totality of their content, due to the attention being focused on their aspects, and actualized in intentional linkage, which is effected through thinking.

The analysis of the origins, thus conducted and understood, enables the elimination of ambiguities that can obscure what is mentioned in concepts, to the extent that it allows the recovery of the path of abstraction, reaching the intuited object. Such procedure of retroactively resuming the path taken in the constitution of concepts, persisted in his thinking, even though he increasingly reached the understanding of the complexity that surrounds the trajectory of such constitution. Within the scope of $P A$, this path goes from concept to intuition of the object, considering the connections of abstracted aspects that occur in thought ${ }^{15}$.

In $P A$ Husserl highlights the genuine symbolic concepts, based in original intuition. They show the concept in symbolic terms. Such matter became the focus of his investigation as he believed the logic of his time to be flawed. This is an important study as it brought up the issue of thinking about logic and acting technically with logical laws. This questioning founded his criticism of the sciences, which operate following the laws of logic. Such criticism was revisited under another guise in The Crisis when he conducted a phenomenological investigation of modern science.

\footnotetext{
${ }^{15}$ Even though this issue may give rise to discussions, which have occupied the minds of mathematicians throughout history, about mathematical notions being discovered, meaning they are outside human capability for thinking about them, or if they are constructed by the human mind; for Husserl all human knowledge and, therefore, the sciences and in them mathematics, are constituted and produced by the human being, understood as a person who, in the living-body (understood in the concreteness of flesh and bone), is constituted in its organic totality by physical, psychical and spiritual dimensions. The former also encompasses sensations, the latter emotional and reasoning states, the spiritual, states of judgment.
} 
He raised the following questions: can the justifications of symbolic concepts, such as the concept of number, be assessed intuitively? What is logical reasoning based on, both in scholastic and algebraic logic?

While working on the issues that he had raised regarding symbolic concepts, Husserl was more concerned with philosophical aspects. His criticism of logic was directed to calculations which, in general, are conducted within the realm of reasoning that relies more significantly on articulations based on rotely applied rules, than in their underlying theoretical bases. He pointed to a significant issue; the justification of the implicit affirmation of symbolic concepts, such as in the case of numbers greater than twelve. According to Husserl, these affirmations cannot be verified through the only method he considered pertinent: concrete intuition, which enables the comprehension of the concept of number. He further explained it is the case of symbolic concepts of numbers, formed by repetitive addition of units. These are represented by signs. Such as: $1+1+1+1 \ldots$, whose series of natural numbers is then transposed onto systematic series, as explained in De Boer (1978).

Symbolic concepts carried out only in thought can be found in this intuitive process. He further explained that as a result of our ability to string together thoughts maintained with symbolic representation, we move further and further away from the original act of intuition, and end up operating solely with calculation rules, stripped of genuine meaning, except for their own rules. The operations conducted become mechanical, successful only with the aid of signals which, in turn, are based on symbols. This procedure is widely known in mechanically performed counting.

Thus, it is understood that mathematics, treated for its particularities of arithmetic and logic, distances itself from reflective thought about its fundaments, and rather becomes highly technical. This is so because concepts and rules are substituted by signs that simplify complex combinations. Thus, on one hand, energy is saved and, on the other, meaning is lost. For instance, in the decimal system, $10+1+1$ is substituted by $12 ; 10+10$, by 20 , etc. We operate with signals, according to the rules of the game. So, mathematics can be seen as a game of signs that may even be words.

\footnotetext{
How, therefore, could one conjoin number concepts in operations, since each remains identically what is; and since each concept in and for itself, is only a single one, how are we ever to conjoin identical concepts?

The answer is obvious; the arithmetician absolutely does not operate with the number as such, but rather with the generally represented objects of those concepts. The signs which he combines in calculating have the character of general signs, signs formed with number concepts as their basis (HUSSERL, 2003, p. 191).
} 
While manifesting his comprehension regarding the fundamental activities of numbers, Husserl stated that they are directly formed solely by the enumeration process; enumeration of things or, recognizing another extension, enumeration of units. However, numbers can also be formed in an indirect way, through calculation operations, which are understood as the fundamental activities of addition and division.

He understood addition as "To add is to form a new number by collective combinations of units from two or more numbers" (HUSSERL, 2003, p.193). Nonetheless, this is a significant issue for arithmetic. It regards each number appearing, in its internal constitution, as one additive conjunction of units or ones. In logic, however, addition of units is not a logic specification or addition in general but refers to one and zero.

Husserl argued that the definition that number is an answer to the question 'how many?' is in tune with the investigations presented in $P A$, regarding the original intuition of number. Nonetheless, he stated that not all answers to that question are admissible, except for those that may be positive. In the case of a negative answer, a no-many or no multiplicity will result, which is a special case of many. Arithmetically one and none are two possible answers to how many. "Linguistically one and none function just like numbers and therefore the grammarian is at liberty to regard them as numerical determination. But logically they are not that” (HUSSERL, 2003, p.138).

Nominally, the concept of number one must be distinguished from the concept of unit or the concept of one. One as answer to "how many?" does not coincide with multiplicity, from the standpoint of the concept. Along with the concept of number, seen as multiplicity, the concept of unit is an inseparable given. However, this is not true for the concept of number one, as a subsequent result to technical development. According to Husserl, "even if such distinctions are a matter of indifference to the arithmetician and justly is so - they nevertheless must be such for the logician" (HUSSERL, 2003, p.142). To the question 'how many apples?' we do not obtain as answer a unity, but one apple, for instance. Thus, the expression of multiplicity of units generally does not mean the same of multiplicity of numbers one. "To identify the two is to attach to the term 'unit', in addition to the many equivocations which it possesses anyway, a new one, from which it is still free in common linguistic usage" (HUSSERL, 2003, p. 143). Husserl's criticism of logic, as well as arithmetic arises from the mechanical way both operate, 
following explicitly the rules stablished for their procedures in a calculative thinking ${ }^{16}$ manner.

Even though many mathematicians and philosophers accused him of being opposed to logic in $P A$, and not recognizing its value, this was not the case. According to De Boer, Husserl was a competent expert in algebraic logic. Through his studies regarding such logic he came to understand that there is no fundamental difference between logic in arithmetic and logic in algebra. ${ }^{17}$ Logic is the theory of correct thought; logic calculation is a method that aims to spare us difficulty while thinking. Thus, calculating is not specified as thought, but as a substitute for thought. That is why operating with signals can become a game of signals devoid of meaning.

His considerations regarding algebraic logic are also valid for scholastic logic that, in his view, had degenerated into a technique for calculating and drawing conclusions.

He believed that

Logic and algebra are completely different theoretical fields. Thus is possible for one and the same person to be a good algebraic technician but only moderately successful, as a philosophy of algebra: the devising and application of a calculus might well be accompanied by a lack of insight into the essence and its cognitive value (DE BOER, 1978, p. 67).

This understanding moved on to the criticism of sciences, brought about in an explicit and concise manner in The Crisis of European Sciences.

The objective of the present section was to explain the ways through which Husserl understood the origins of number in Philosophy of Arithmetic, as well as indicate that, at that time, the criticism towards sciences, especially mathematics and, within its realm arithmetic, was already occurring. The criticism he endured from mathematicians, mainly Frege, regarding founding arithmetic in psychological acts was scathing. For Husserl himself it became challenging to account for the logic that underlies the theory of arithmetic. In the 1890s, his investigations focused on logic, resulting in the publication of Logic Investigations (Logische Untersuchungen - LU) ${ }^{18}$, in 1900/1901. ${ }^{19}$ The objective

\footnotetext{
${ }^{16}$ It is interesting that this idea brought up by Husserl in $P A$ will be revisited by Martin Heidegger in the article Discourse on Thinking (1962), when he develops the argumentation regarding calculative and meditative thinking.

${ }^{17}$ Husserl would further elaborate the arguments regarding this matter in Philosophy of Arithmetic, with "higher operations" and Logic Investigations, volumes V and VI (HUSSERL, 2008).

${ }^{18}$ In this article I will use $L U$ to refer to Logic Investigations.

19 First published in German as Logische Untersuchungen by M. Niemeyer, Halle 1900/1901 Second German edition, Vol. I and Vol. II, Part I, first published 1913 First published in English 1970 by Routledge \& Kegan Paul Ltd Reprinted 1976, 1977, 1982 This paperback edition first published 2001 by Routledge 2 Park Square, Milton Park, Abingdon, Oxon OX 14 4RN Simultaneously published in the USA and Canada by Routledge 270 Madison Ave, New York, NY 10016 Reprinted 2002, 2003, 2005, 2007, 2008 Transferred to Digital Printing 2008. Routledge is an imprint of the Taylor \& Francis Group, an informal
} 
of that work was clarifying the concepts of pure logic. Pure in the sense that it is founded in the essences ${ }^{20}$ or eidos. In the section dealing with the origin of geometry, I will focus on his understanding of essence, aiming to show that he had already theoretically distanced himself from Brentano.

Husserl believed that knowledge and specifically the science with which he worked, should not be based on theories that offered assumptions to support deductions and inferences to produce new theories, and conducted his work accordingly.

On the contrary, the attitude proposed by Husserl is to work from the bottom up (Von unten). The absolute principle, to be understood in this case as the genesis of essential knowledge and, therefore, as a foundation, notwithstanding only in the sense of valid knowledge, can be expressed by the well-known formula 'principle of all principles' (emphasis added by the author of this essay), according to which 'all originally offering view is a legitimate source of knowledge, that is, all that is originally presented in intuition (in the flesh, so to speak) must be accepted as presented, but also solely within the limits in which it is presented (ALES BELLO, 2000, p.38/39, author's translation )

In Prolegomena - LU, (HUSSERL, 2008) Husserl already presented concrete collectives - regarding categorial perception that offered examples of specific cases of ideals.

The changes conducted regarding the origin of numbers appear to be a significant insight, that I understand as the germ of the later developed eidetic phenomenology. The origins of number no longer lie in the act of collecting, but in the correlated eidos, as this phenomenology recognizes that such act only spawns the concept of collecting. According to De Boer (1978)

Through the doctrine of numbers as ideal entities, Husserl honors Frege's criticism of his 'psychologism'. Although Frege did not distinguish the various forms of psychologism and unjustly accused Husserl of reducing contents to acts, Husserl must have felt that here Frege's criticism really did apply to his philosophy of arithmetic. Arithmetic concerns itself not with psychical facts but with ideal entities. The mathematical and the psychological belong to 'such different worlds that the very thought of interchange between them would be absurd (DE BOER, 1978, p. 280).

My intent is to go from his first significant work, Philosophy of Arithmetic, to The Origin of Geometry, presented as an appendix to his last significant work, published in 1937, while he was still alive, The Crisis of European Sciences and Transcendental Phenomenology (HUSSERL, 1970).

business Translation (C) 1970 J. N. Findlay Preface (C) 2001 Michael Dummett. The citations from LU in this article come from "Husserl, Edmund. Logical Investigations Volumes 1 and 2 (International Library of Philosophy). Taylor and Francis. Kindle edition".

${ }^{20}$ It is important to reiterate that his conception of essence is not the same as that of Plato. 
A relentless thinker at the same time concerned with his affirmations as well as with the method and procedures to make such affirmations, Husserl travelled a long journey between these two works. His concern with method lead him to incessantly revisit what had been realized, exposing objections, and explaining his insights to solve them. This shows his dissatisfaction with what had been obtained and his insistence in declaring important work such as Ideas I (HUSSERL, 1931), and Cartesian Meditations (HUSSERL, 1977), as "introduction to phenomenology". ${ }^{21}$

\title{
3 The origin of geometry, the critique of european sciences and the concept of history
}

In the first paragraph in Appendix VI, The Origen of Geometry, of the Crisis of European Sciences (HUSSERL, 1970), Husserl set out his goal for that text. I particularly consider it a sui generis essay, as it represents a synthesis of his thinking and understanding of science from the perspective of the way it is constituted and produced. To this end, he uses geometry as an example to show his understanding. In the core of his phenomenological thinking, synthesis was always understood as being transitional, since it does not solve the questions and doubts pursued in the arguments articulated to answer them. Rather, in the very movement of thinking, and by thinking, he opened himself to other questions, other doubts, he pointed to obscure passages and established the urgency of pursuing the investigation.

In the following paragraphs he explained his objective:

\begin{abstract}
Rather, indeed above all, we must inquire back in the original meaning of the handed-down geometry, which continues to be valued with this very same meaning - continued and at the same time was developed further, remaining simply 'geometry' in all its new forms. Our considerations will necessarily lead to the deepest problems of meanings, problems of science and of the history of sciences in general and indeed in the end to the problems of universal history in general; so that our problems and expositions concerning Galilean geometry take on an exemplary significance (HUSSERL, 1970, p.353).
\end{abstract}

\footnotetext{
21 The metacomprehension he performs throughout his investigation, in order to understand the methodological procedures he conducted that led him to expose his studies in his published work, as well as the many notes he wrote, would lead to transcendental phenomenology, to assume the perspective of transcendental reduction, and then undergo a radical change regarding his view of reality and the ways to study it. From 1913, when Ideas was published, to 1916, there was unsettlement among his students. Heidegger, Edith Stein, among others, criticized him because they believed he was completely departing from his bond with reality and becoming too 'idealistic'. However, that was not the case, as will be demonstrated in the section dealing with the origin of geometry.
} 
Why geometry and why Galileo to start this "archaeological excavation" work in search of the depth of the problems of the meaning of "origin", now focused on the physics of modern times?

The difference in terms of the way of viewing and seeking to understand origin already stood out when mentioning physics, a modern science, whereas in the PA he sought the origin of the number in the subjectivity of psychological acts performed by the subject. We have seen that many of Husserl' critics fixated on the importance that, in that phase of his life when he worked on $P A$, he attributed to subjectivity to explain his understanding of the objectivity of numbers. However, when he changed his focus from the origin of number to origin of geometry, a theoretical abyss can be seen: on one margin of this abyss are the theoretical considerations on the origin of number based on psychology, and, on the other side of the gap of this deep and apparently empty chasm, are the considerations on the origin of geometry wrapped in historical complexity.

Would he have completely changed the course of his investigation?

This was not the case, for as early as the 1890s, his writings revealed that psychology displayed a connection with mathematics. Many of such writings were not published while he was alive. They were published postmortem by scholars who dedicated themselves to the unpublished works found in the archives of the Husserl Library in Louvain. Ales Bello argues that, in seeking to [...] clarify the constitution of mathematical concepts, psychology plays a role of "clarification and analysis: in fact it examines how certain key concepts are shaped such as those of number, space, continuous, magnitude, situation, shape" (ALES BELLO, 1986, p. 41-42 - author's translation).

Clarifying the scientific concepts is the appeal to which Husserl responded and which remained alive and active throughout his professional life. He wanted to understand how and why science is produced, using, as previously mentioned, geometry as an example. By committing to this undertaking, he highlighted the importance of descriptive psychology as a methodological resource, since it contributes to the description (Aufklärung) of the origin (Ürsprung) of concepts of logic with the descriptive method; moreover, it opens horizons for a radical move from descriptive psychology to phenomenology. However, his critique of psychologism, which intends to support the foundations of pure or formal logic, persisted. When he referred to psychologism or historicism, he referred to the vision of both, psychology, and history, taken as factual and in line with positivism. Throughout his journey, from Philosophy of Arithmetic to 
Logic Investigations, changes were made which advanced from descriptive psychologic phenomenology to transcendental phenomenology.

We have seen in $P A$ that the psychical phenomenon is intuited in the act that apprehends its content through perception. It is an act resulting from the subject focusing his attention on the phenomenon. In $L U$, it is the object that appears to consciousness as perceived, as givenness-sense from the perceived thing. It is the fruit of an intentional act; therefore, no longer derived from psychological attention. Thus, the object is viewed as intentional. This is a significant change because consciousness stops dealing with the content of the object and starts dealing with the essence or eidos and, thus, performs the acts of knowledge with ideas.

How does this change take place? Husserl no longer understood consciousness as a psychical phenomenon, therefore belonging to the external reality of the subject, just as he conceived while working with the Brentanian view; rather he understood it as internal to the subject, as one of the subject's regions. Consciousness targets the phenomenon (object of the external world) and, through intentionality, perceives the phenomenon, which now comes as an idea (essence) and no longer as content of the object. This is the noesis-noema ${ }^{22}$ movement, which is so striking in Husserlian phenomenology.

The change in perspective regarding reality and knowledge from descriptive psychology to essential phenomenology and transcendental phenomenology is a movement that extended from the 1890s to 1913, culminating with the publication of Ideas (HUSSERL, 1972). It covers the epoché, also called Reduktion and Ausschaltung, which allows the realization of eidetic reduction, typical of essential phenomenology, and transcendental reduction, typical of transcendental phenomenology. Reality is no longer regarded as physical phenomena and psychical phenomena; it is merely a reality external to the subject. Husserl did not propose to tackle it, because he understood that this was not possible and, at that stage, he did not even consider studying it. His goal was to investigate the ways through which knowledge takes place.

One cannot avoid considering that knowledge is about reality, but about which reality? The question I am asking will be explained throughout his work. I will return to it in this essay, when I present the understanding of the origin of geometry.

${ }^{22}$ Noesis concerns the acts performed by the consciousness, while noema concerns the thing focused by the intentional look. 
Reduction is a voluntarily act performed by the subject, in an action that does not intend to build or explain something, but only to let oneself be carried away by something, intentionally focused on seeking to understand it beyond what can be seen immediately. It is a search that takes place as a silent response to what torments the subject, impelling him to go on, to unravel the mystery that is announced beyond sight. It is a movement focused on the givenness-sense of the thing in its ways of givenness. These ways of showing itself in its characteristics, such as the coldness of ice, the redness of the color red that shows itself in an object in varying luminosities, the rough sound of a stone falling onto another, or the shrill of a piece of metal hitting another, the roughness of a thorny surface, etc. This givenness can be perceived by the senses of the subject who perceives, in different nuances, depending on the moment the subject experiences it, as well as according to the greater or lesser acuity of possibilities for feeling of the organism of the subject themselves. ${ }^{23}$

By means of reduction - which may either be eidetic or transcendental attention is shifted from factuality to essentiality. It is a movement to place in suspension what one seeks to know and forsake a priori beliefs and concepts that postulate about what is investigated. In eidetic reduction, the reality of the factual world is forsaken, as if it were disconnected from the focus to which the subject steers their intentional gaze. Husserl did not deny this reality; moreover, he stated that nothing is lost in this reduction. He saw the residue that remained in this epoché as "[...] is not reality itself but a psychological sense to which we retreat because true reality is inaccessible" (DE BOER, 1978, p. 472). The reality dealt with by the subject in the acts of consciousness is not a representation of the factual and objective object; but rather an ideal presentation, as it is derived from the movement of noesis-noema that brings it as its essence. The idea or essence understood in this way is not a fantasy; it has its own objectivity. It brings with it the thing, the noema, perceived as a unity of meaning apprehended in the ways it offers itself. The consciousness we are talking about was understood by Husserl, in that phase of his professional life, as a region of the subject.

\footnotetext{
${ }^{23}$ In Idee vol. II, Husserl explains the understanding of the living-body, explaining in detail the intertwining of the different sensations - tactile, visual, auditory, gustatory, olfactory, of kinesthetic movement, as they are always intentional - among themselves and with other cognitive and judgmental acts which occur in the carnality of such body. The comprehension of the living-body and its respective experiences are important contribution made by Husserl that affected philosophy, psychology as well as contemporary social sciences.
} 
The residues left in the eidetic reduction remain as a question that, in a silent way, inhabited his investigations and, little by little, came to be outlined as an answer that came with his understanding of the world and that, in the works conducted during his more mature phase, were included in the conception of life-world (Lebenswelt), when they no longer remained simply as residues. In addition to the residues that remain with this epoché, the understanding of consciousness as one of the regions of a person also populates his theoretical concerns. This question became clearer, arising in an insight that led to the collapse of the naturalistic world view. These concerns became evident as he realized a metacomprehension of the methodological procedures present in his investigations. As previously mentioned, his goal was to understand how he realized that, what his investigative procedures were and, thus, also be able to validate a possible and, for him, crucial perspective, which is that of critical, i.e., radical reflection. When making efforts in this direction, emerging from a deep dive, he clearly realized that consciousness could not be considered as a region of the person as it is assumed in eidetic reduction, but that it had to be understood as non-regional, fluid, moving consciousness, as an originator of meaning, so that it could reflect about itself. Here we see the radical change brought about by transcendental phenomenology that causes the collapse of the naturalistic conception of the world which is understood as an objective reality and external to the subject. Radical reflection concerns the consciousness taking itself as a phenomenon, placing itself in epoché and reflecting about itself. This change in his phenomenology, which boomed from 1913 to 1916 in Göttingen, caused dissatisfaction among his disciples. This dissatisfaction of his disciples ${ }^{24}$ revolved around their understanding that, with the views about transcendental reduction, especially regarding consciousness as an absolute principle of meaning, Husserl was changing the perspective of phenomenology with which he had been working up to that point. According to them, he was heading towards an idealism that indicated, as they saw it, a trend towards a solipsistic closing of consciousness. ${ }^{25}$

Back to consciousness. To an unsuspecting glance, consciousness seems to be revolving around itself, working with contents devoid of signs of the external world. However, this is not the case. How and why? What does it realize? The living experiences

\footnotetext{
${ }^{24}$ Among such disciples, who drifted away from Husserl and followed different theoretical paths are: Martin Heidegger, Edith Stein, who in turn indicates, according to Ales Bello (2000, p.50), Max Scheller, Alexander Pfänder, Adolf Reinach, Hedwig Conrad-Martius and Jean Hering.

${ }^{25}$ It is worth pointing out that this type of criticism is still repeated to this day by readers with superficial knowledge of his work.
} 
and the acts themselves which, when performed, actualize what is intended in them. Due to the objective of this text I will only point out important understandings that are present in the concept of living experience (Erlebniss) ${ }^{26}$ and that, as I understand it, eliminate the possibility of a solipsist circularity of consciousness. They are the conception of livingbody $^{27}$, living-experience (explained in footnote 26 ), intropathy ${ }^{28}$, intersubjectivity ${ }^{29}$, and pure ego ${ }^{30}$.

In a continuous flow, consciousness records experiences, realizing them. To do so, it can no longer be understood as a region of the person. It should be in all regions of the living-body, recording occurrences, operating as a center for meaning and as a

\footnotetext{
${ }^{26}$ The living-experience (Erlebnisse) speak, at first glance, about the life that flows, as it is lived. We live experienced acts in motion for the duration of their temporality. At each moment we live the present moment of the act taking place. Psychical acts, such as perceiving, imagining, fantasizing, remembering, reflecting, which are inherent to human beings, even if they occur uniquely in separate individuals. Living experiences flow, slips from now to what has been, making room for other living experiences. We know we are living, but only by an act of consciousness do we realize what we are experiencing. This act is to perceive the experience as being lived and Husserl calls it "Erlebniss".

${ }^{27}$ Living-body is a temporal and spatial complexity because it is always here and now, in its carnality, although we understand that by remembering one can refer to past experiences, living them through remembrances. One can imagine, fantasize, and wonder through the spaces thus opened to the activities of thought. As it is temporal, it lives in the historicity, temporality that extends through its acts in actualization, that is, in action. Actions that are performed and expanded in spatiality. It is the incarnated body, the intertwined totality of physical (relative to the organism), psychical and spiritual activities. Physical activities display the structure and operation of different organs, their neurological and chemical aspects, the sensorial organs; psychical activities refer to emotions, pleasure, pain, as well as cognitive and spiritual reasoning; they speak about acts of judgment, such as greater, smaller, more beautiful, uglier. Its characteristic is to be an intentional movement, which sets the tone for their occupation of space and actions: the subject is always in the process of doing something, responding to something, going towards, revealing an attitude, a way of being present. It is the presence of the person in flesh and blood. At the same time, the person "exposes" herself in it and brings the external world into it, including the other, into their internal reality. I understand that an abyss is opened when we realize the complexity of the living-body. What is internal brings what is external and the self, and acts of consciousness... the possibility of knowledge. The connection with the external world and the pole of a dialectic "me - other", in which the intersubjectivity constitutes "me" (my living-body) - the other (their living-body) just like me because they can also see me as an "other", feel, expose ... and different from me. This pole, in all the complexity of this living-body, opens to the other primarily through this intropathic act, as well as language.

${ }^{28}$ Intropathy is knowledge of the other that occurs directly in the experiences in which the other is given (brought, exposed) to the self in its corporeality. It is a constituent perception of intersubjectivity. It is not, therefore, a theoretical concept or a predicatively constructed statement.

${ }^{29}$ Intersubjectivity is the reality constituted by the subject (living-body) being with another subject (livingbody) in the life-world in which they are. It is in this dimension of reality that social organization is produced, as well as science and all the socio-historical materiality that is produced and that is there to bring sense for a subject who is willing to understand it. In Cartesian Meditation - An Introduction to Phenomenology (HUSSERL, 1977), in the Fifth Meditation, Husserl exposes his thinking about the way in which the other is constituted for the subject. Following his conception and proceedings, phenomenology seeks to understand how the object is constituted by the subject, to make sense for them. In the case of the other human being, this procedure is also performed.

30 "Pure ego" is not the same as human personality. Nor is it given in the order of manifestations in relation to phenomenic circumstances. It is an absolute ipseity and takes place in its unity deprived of evidence; it can be appropriately apprehended through a reflexive conversion of the view that highlights it as a center of functions. While pure ego, it does not hide inner secrets and wealth itself, it is utterly simple, it is utterly enlightened; all wealth is in the cogito and in the modality of its functions and, in that it can be appropriately understood (HUSSERL, 2002, p. 109, author's translation)
} 
performer of the reflective act. Husserl, in the insight mentioned above, sees it as a thin, transparent, invisible tissue. "[...] (consciousness) can be understood by means of the image of a clear glass screen on which one inscribes what we experience in a continuous flow of inscriptions (ALES BELLO, 2011, p.119)". It operates as a functional pole of knowledge, then becomes absolute as it turns itself into a generator of sense to the living being, while actualizing the acts it performs. These are acts that occur in the carnality of the living-body, which is intentional and always moves towards something to be done. This is understood here not only as a physical act, but as any intended activity; thinking, fantasizing, imagining, etc.

The concern imposed to Husserl that led him to carry out this whole movement of constitution of phenomenology, was of an explicitly epistemological nature. He wanted to know how the meaning of the world was constituted for the subject, highlighting, even when he exposed transcendental reduction, the reality brought about in the acts of consciousness. As explained before, it regards ideal reality, as, when perceived, reality is entwined in intentionality as eidos, thus giving way to idealization.

The search that placed him in this movement was for understanding the constitution and production of science. His goal was to realize the concept of philosophy which he understood, at the beginning of his work, as making scientific concepts clear. Initially, as previously explained in this article, he focused on mathematics; within mathematics he focused on Analyses of arithmetic, and within it he focused on number. In this movement he was launched beyond science, entering the tortuous paths of understanding the person, the person's development, the ways in which the reality of the world makes sense to the person, how this sense is expressed and shared with others with whom they are, and even the reality itself in which science remains in historical-cultural production.

He is aware of the crisis affecting modern science. In the 1880s, 1890s and 1900s, he specifically placed in epoché the crisis of the fundaments of mathematics. In the 1920s and 1930s, he focused on the crisis shaking Europe, in social and historical terms, but he continued to worry about science. At that time, his conception of philosophy was more comprehensive, and he was led by it: "[...] philosophy is "to teach us how to carry out the eternal work of humanity'. It must not only enlighten man about actual states of affairs, it must also provide leadership in ethical and religious matters" (DE BOER, 1978, p. 497). On May 7 and May 10, 1935, he gave a lecture before the Vienna Cultural Society, with the original title of "Philosophy in the Crises of European Mankind". In 1922, he had 
already expressed this concern in the article published in the Japanese journal Kaizo (HUSSERL, 2006). Therefore, it was about conceiving this crisis as teleologicalhistorical. In footnote number 1, on page 3 of Crisis, he expressed it as follows:

\begin{abstract}
The work that I am beginning with the present essay, and shall complete in a series of further articles in Philosophia, makes the attempt, by way of a teleological-historical reflection upon the origins of our critical scientific and philosophical situation, to establish the unavoidable necessity of a transcendental-phenomenological reorientation of philosophy. Accordingly, it becomes, in its own right, an introduction to transcendental phenomenology (HUSSERL, 1970, p. 3).
\end{abstract}

This is a task that led him into the crisis then installed in Europe, searching for its origin, understanding that it is within the sciences themselves, exact and natural, but also in the humanities. His analyses led him to understand that these sciences, as much as they have developed on the basis of the exactness of their theories and the certainty that supports their statements, to a lesser degree present in psychology, have nothing to offer to man about his rational or irrational ways of being, of being free and of living in the dimension of rationality and freedom. He stated "Scientific, objective truth is exclusively a matter of stablishing what the world, the physical as well the spiritual world, is in fact" (HUSSERL, 1970, p. 6). To the sciences which assume this perspective, the historical occurrences are understood as an unending concatenation of illusory progress and bitter disappointment.

Therefore, the shift in his investigative concern is clear, leaving behind the origin of the concepts studied in the dimension of the subjective psychical acts and starting to focus on the expression of the articulations of sense understood by the subject and communicated in the intersubjective sphere, going towards the life-world (Lebenswelt) and its teleological/historical reality. Within this understanding of reality, he investigated the origin of the crisis, whose core he believed could be found in the metaphysical view of the positivist sciences that postulate about the reality and the way man should be. He believed that the philosophy of positivist sciences that was established in the movement of revival of metaphysical philosophy of the Renaissance destroys philosophical thinking. It was established at that time, and persisted in the following centuries, especially the 18th century, self-styled "century of lights", when it becomes evident:

[...] the ardent desire for learning, the zeal for a philosophical reform of education and of all humanity's social and political forms of existence, which makes that much abused Age of Enlightenment so admirable. We possess an undying testimony of this spirit in the glorious 'Hymn to Joy' of Schiller and Beethoven. It is only with painful feelings that we can understand this hymn today. A greater contrast with the present situation is unthinkable" (HUSSERL, 1970, p.10). 
He argued that the new sciences undoubtedly seemed initially successful when they exposed their favorable results by applying their theories. However, he considered that this initial impetus was giving way to a feeling of failure. This is the beginning of "a long period extending from Hume and Kant to our time, of passionate struggle for a clear, reflecting understanding of the true reasons for this centuries world failure" (HUSSERL, 1970, p.11). He stated that sciences dissolve internally because they do not understand the meaning of their original foundation when it appears as a branch of philosophy. That means that when they separate themselves from philosophy, they stop thinking philosophically about their meaning, what they say about the world, mankind, and life itself. Thus, a crisis is set, initially latent and later acute, of the European community that speaks of the lack of meaning of its cultural life, viewed in terms of its total Existenz.

While reflecting on this problematic situation, he focused his views on human history, looking at the present. He stated "we can gain self-understanding, and thus inner support, only by elucidating the unitary meaning which is inborn in this history from the origin through the newly established task (of the Renaissance), the driving force of all [modern] philosophical attempts" (HUSSERL, 1970, p. 14).

He believed that it was necessary to revisit, in a critical manner, the historical path following the trail initially sought by philosophy. Thus, he put in epoché the origin of the new idea of the universality of science in the reshaping of mathematics. In carrying out this investigation, he explained the basic transformation of the idea of universal philosophy that arose at the beginning of the Modern Age, from Descartes onwards. The view that prevailed was that of an infinite world obtained by a rational, coherent, and systematic method. With such view, an infinite horizon was opened to mathematics. It supported the sciences, both through the possibility of applying their theories and by serving them as a methodical and ontological basis. Husserl called the presence of the ontology of mathematics in science the mathematization of nature. In $\S 9$ of Crisis of European Sciences, he provided a magnificent exposition of this mathematization, by presenting the way in which Galileo theorized modern physics, as he sees it.

He questioned how did a shift in gaze, and practices, theoretical or not, occur, which deviates from the daily living-experience in the life-world about the reality which is given subjectively, to the way of viewing the world through the filter of geometric exactness? Going backwards from the present to the point of radical change in terms of the epistemological and metaphysical perspective that paved the way for philosophical 
and scientific knowledge since ancient Greece, he found the turning point in Galileo. He put Galileo and his philosophy and practice into epoché and, through a full analysis, clarified the ideas that Galileo used. What Galileo had at hand as pre-data knowledge available and that reached his time and his culture by tradition was Euclidean geometry. He understand tradition as carrying acquisitions historically sedimented and offered to those who are interested in them; they can be revisited and improved in the interior of the whole itself, which is thus brought about. In the specific case of Galileo considered herein, the acquisitions offered to him refer to mathematics and its respective praxis.

Galileo assumes mathematics in terms of Euclid's geometrical theory which deals with space understood as an exact space and not one uncertain which comes from the appearance of worldly objects. When he conducts this shift in the concept of space, then the space with which the science of physics deals becomes an exact space. Thus, mathematics provides the accuracy that underpins certainty. Geometry brings the exactness concerning geometric space, allowing applications directly to the reality of the physical world. Galileo, as Husserl interprets his way of dealing with Geometry, opened the horizon of practice, without reflection on the original intuition that is at the core of the production of knowledge that has been established. In this blind application, with no reflection on its meaning, natural sciences (and, as a result, sciences in general) gain accuracy and can work with the invariance of geometricized space. Then, they move away from the imperfection of shapes perceived by people in empirical practice, as well as from the inconstancy of a reality that is always in motion, just as in motion is the subject that perceives it. Pure geometry becomes "applied geometry, a means for technology, a guide in conceiving and carrying out the task of systematically constructing a methodology of measurement for objectively determining shapes in constantly increasing 'approximation' for the geometrical ideals, the limits-shapes” (HUSSERL, 1970, p. 2829). The direct application of geometric shapes and formulas to physics leads the subject to distance themselves from the world of living-experience; moreover, it fosters distrust and non-acceptance of the original intuition, replaced by the accuracy and certainty of science.

I believe that here there is a forced cut in the realm of positivist sciences. The truth is dictated by scientific theory, which postulates about mundane reality. It is beyond experienced reality and the experiences of subjects who, in their sensitivity, perceive nuances that are discarded by scientific theory. This cut entails a schizophrenic vision, because the subject needs to deny their sensitivity and perception and impose the 
"scientific" truth upon themselves. Beyond this understanding, the question remains silent: how is science generated and who generates it? Husserl believed that the meaning of mathematization of nature:

\begin{abstract}
does not lie in the pure interrelations between numbers (as if were formulae in the pure arithmetical sense; it lies in what the Galilean idea of universal physics, with its (as we have seen) highly complicated meaning-content, gave as task to scientific humanity, and in what the process of its fulfillment through successful physics results in - a process of developing particular methods, and mathematical formulae and 'theories' shaped by them (HUSSERL, 1970, p. 41).
\end{abstract}

With exactness, obtained through measurement, the conception of number obtained in a scale is originated. Now, there is a change in the very structure of mathematics. The effects of algebra and its way of thinking, which is widespread in modern times, are revealed. Arithmetic thought, along with algebra, as Husserl had already clarified in the $P A$, moves away from all original intuition regarding numbers, from numerical relations and numerical laws. This reduction of thinking rapidly extends to all geometry, to pure mathematics, to formalized algebra itself.

Galilean spirit expanded from physics to natural sciences, emptying itself of its original meaning and leading to an all-embracing universalization. It expanded from physics to the other natural sciences and from those to spiritual sciences, among which psychology and history, with which Husserl had struggled since the beginning of the 20th century. Galileo's idea consisted in seeking validation in knowledge of proven hypotheses, according to established procedures. Thus, the knowledge of science would advance from hypothesis to hypothesis and remain as an endless chain of verifications. Newton stated: “[...] the ideal of exact natural scientists, says 'hypothesis non fingo', and implied in this is the idea that he does not miscalculate and make errors of method" (HUSSERL, 1970, p. 42)

When Husserl interpreted analytically and reflexively this phenomenological analysis, he exposed his understanding of what lies beyond it: the recurring prediction, which extends to infinity ${ }^{31}$. He also believed that the erroneous understanding of mathematization brought about at least two conceptions that have developed and persist to this day. One regarding the subjective character of the sensitive qualities that led Hobbes to formalize it as a doctrine of the subjectivity of the concrete phenomenon of an intuitive nature and of the world in general. The other conception regards nature as seen,

\footnotetext{
${ }^{31}$ Infinity understood in the common sense, as extending without interruption, without turning back and
} asking what this science says about the world, about man, about life. 
in its own being, such as mathematics, from which derives the certainty that the knowledge produced by natural sciences is valid and speaks of the totality. Mathematics, in turn, assumes itself as the way nature is, and envisages itself as powerful.

\section{The meaning of origin of geometry}

Husserl understood the origin of geometry based on the original intuition of a subjectivity and on the historical a priori. It is in the interweaving of these two conceptions that resides the singularity of the way he viewed origin in that period.

Given the theme of this article, I will focus on history, which brings about the idea of horizon and of life-world, as well as enables questions about his phenomenological vision, including transcendental phenomenology.

In the 1930s, he turned intensely to the question of history, studying it from the perspective of transcendental phenomenology. The origin, in this final phase of his life, is understood within the framework of a complexity in which the reality of the world, understood as life-world, historical a priori, horizon, language, and tradition are intertwined. At the same time, he was concerned about the crisis of European philosophy ${ }^{32}$ and his understanding of the renovation of this philosophy, already expressed in Kaizo, in 1922 (HUSSERL, 2006). He believed that in the investigation of this origin the following elements intertwine:

[...] understandings and expressions/understandings among subjects, who, through language and tradition, remain present in the historical-cultural world, which can also be understood as the world of the historical a priori where we live within the surroundings of what is there as a given (BICUDO, 2016, p.22).

Throughout his work, the origin, was always understood as an originating intuition (Ürsprung), an act in which clear evidence of the intentional object is provided. This is brought to consciousness as the presence (presentation of the idea) that occurs in the very moment. In this instant, the intentional object is presented to consciousness as idea (essence) without intermediation of the sign that can point to and express the intuition. "This perception, or intuition of oneself in presence, would not only be the instance in which "signification" in general could occur, it would also ensure the

\footnotetext{
32"The spiritual shape of Europe" - what is it? It means showing the immanent philosophical idea of the history of Europe (spiritual Europe) or, similarly, its immanent teleology, which makes itself known, from the point of view of universal humanity as such, as a rupture and the beginning of the development of a new age of man, the age of humanity, which from now on no longer can live nor wants to live except in the free formation of its existence, of its historical life, from ideas of reason, from infinite tasks. (HUSSERL, 2008, p. 322).
} 
possibility of an originating perception or intuition in general, that is, the nonsignification as a "principle of principles" (DERRIDA, 1994, p.70) ${ }^{33}$.

Therefore, the origin occurs in a subjective dimension, in the movement of constitution of knowledge. In the subjectivity of the subject is in progress the understanding of the sense of what is perceived and its articulation in a comprehensible unity that can be expressed by the subject for himself and for the other. It is in the expression act that language is present, bringing its signs and symbols, as well as its logical form, enabling both the communication among subjects and the socio-cultural production of knowledge. Such communication demands, besides language, the entropathic perception, both constitutive of intersubjectivity. According to Derrida, through the example of geometry, Husserl wanted to show that the present moment offers: "[...] the very ideal and absolute certainty that the universal shape of all experience (Erlebiniss), and therefore all life, has always been and will always be the present. There is and there will only be the present. The being is presence or modification of presence" (DERRIDA, 1994, p.63).

I believe that in the now the subject has a clear vision of what comes to him in intuition. But the present is only an instant that slides into the past and brings the yet to come (future). In this flow of intentional experiences, consciousness, as understood in transcendental phenomenology, registers them. What is intuited or perceived can be revisited by the subject, who experienced it, in an intentional way, in response to a decision to bring it, through remembrances to the then present moment. This flow is dynamic, it is a movement that is always occurring in the living-body, therefore in its carnality. This movement of constitution of knowledge is pre-predicative, it occurs in the hyletic dimensions, therefore sensory, psychical, and spiritual.

To become a form that exposes the unity of meaning actualized in this movement, when knowledge is so constituted requires language. It is used to express the sense that was made for the subject in this articulated movement, given the functional character of consciousness. However, it brings with it the signs, the symbols conveyed by words and the logic of the grammar of the language of the culture of the world which the subject (where this movement takes place) inhabits. The polysemy of words is rooted in this

\footnotetext{
${ }^{33}$ It is worth pointing out that, in this excerpt, Derrida mentions "principle of principles". I wondered if he was mentioning more than one "principle of principles" in Husserl's philosophy. But I realized that intuition is the actualization of an act in which evidence takes place immediately, without mediation of signs. This is so, because it is direct, and brings into perception what is perceived in the flow of experiences recorded.
} 
movement of expression. Words always express less of the meaning that the subject intends to impart, and more about what they intend, as they carry other meanings expressed in the historicity of the life-world. Thus, language is a living organism. It expresses the intertwining of what is intentional, what is said by the voice, what remains in historicity by tradition, as it can be written or recorded through different mediatic technologies. Moreover, and more significantly for the production of sciences, language sustains logical activity, since it is specifically linked to language, as well as to the ideal cognoscitive configuration that is specifically generated within it.

The explicated judgement becomes an ideal object capable of being passed on. It is this object exclusively that is meant by logic when it speaks of sentences or judgements. And thus, the domain of logic is universally designated; this is universally the sphere of being to which logic pertains insofar as it is the theory of sentences [or propositions] in general (HUSSERL, 1970, p. 364).

Then, the act can objectively be consummated.

It becomes ideally objective and, as such, capable of being transmitted and resumed passively by consciousness or in active production mode, when it is possible for consciousness to intentionally reactivate the original spiritual act, and the iteration of the ideality that then would occur within the subjective sphere, now extended to the intersubjective sphere, moving into the chain of repetitions of what is identical (BICUDO, 2016, p.40).

Thus, language transposes the judgments, in the form of propositional logic and the respective grammar, allowing premises and what they say to be linked in a rational connection, deductive or inductive. The ideas, now formally conveyed, remain in their historicity within the culture of the surrounding world, and can be reactivated in search of comprehension of the original evidence, if those who reactivate them choose to do so.

However, it must be pointed out that Husserl, in The Origin of Geometry (1970), stated that this is not the common way for people to get acquainted with scientific theories. The most common is for people to take their statements as given and repeat such statements without questioning what they convey about the world. By doing this, they may even develop scientific theories, in the direction given by logical progression, or apply them.

\footnotetext{
The progress of deduction follows formal-logical self-evidence; but without the actually developed capacity for reactivating the original activities contained within its fundamental concepts, i.e., without the 'what' and the 'how' of its prescientific materials, geometry would be a tradition empty of meaning; and if we ourselves did not have this capacity, we could never even know whether geometry had or ever did have a genuine meaning, one that really be 'cashed in' (HUSSERL, 1970, p. 366).
}

Modern sciences are constituted and produced through this conduct. They come to our present through historical-cultural tradition which also brings about "the world of 
products transmitted, acquisitions of previous activities, and of forms transmitted while acting with meaning, as a culturally objective happening" (HUSSERL, 2008, p. 522).

This is the world of historical a priori. This is the a priori of the being of humanity and of the world which surrounds it, which is valid for its experiences, thought and actions. It concerns the way of being of man and the world, as the individually understood subject is always in the world, that is, as a living-body who in their carnality lives here (in space) and now (in time), which stretch through a horizon of past events and that are announced in what is to come, therefore in the surrounding-world-of-things-and-culture. Which is

[...] the world of transmitted products, acquisitions of previous activities and transmitted forms of acting with meaning, as an objective cultural happening. However, people and the entire personal horizon for each person belonging to the surrounding world are correlated, and who are in it with personal spirituality configured in the action and from it (as essentially determinant spiritual estate), and that in the present act continues to develop today (HUSSERL, Anexo XXVI, 2008, p. 522).

Such finding led Husserl to assert that "Historicity in this broader sense has always been in progress and, in its course, is precisely a universal that belongs to human existence" (HUSSERL, 2008, p.523). As humanity, we belong to this world and, each one of us, are in it and are with it, being with others, seeking to understand it. It is an intuited world, a living-world in which we are both as ordinary people and as scientists, whatever the case. "The life-world is always there for mankind before science, then, just as it continues its manners of being in the epoch of science". (Husserl, 1970, p. 123)

By focusing on geometry, Husserl took it, from the present, as a guiding thread to pursue its historical tradition, as he understood that when geometry is given in the present life-world, it brings with it all the historical-cultural tradition that, through the sedimentation of idealizations and theoretical formalization, came to be consolidated into a theoretical body, called geometry. It is in this present; being in its own manner of being, nonetheless, it cannot be understood in an isolated and transient way, but in the horizon of its historicity.

[...] Carried out systematically, such self-evidence results in nothing other and nothing less than the universal a priori of history with all its highly abundant component elements.

We can also say now that history is from the start nothing other than the vital movement of the coexistence and the interweaving of original formations and sedimentations of meaning (HUSSERL, 1970, p. 371).

Thus, the issue of historical a priori that accompanies the movement of lifeworld and that is also an a priori of history which, in turn, is the a priori of scientific 
knowledge. But, as explained above, that is a chain that involves spiritual acts and psychical acts, therefore of individual and corporeal subjectivity. That is, of a subjectivity that performs acts, which are historical in double measure: because historicity is a universal belonging to human existence and because this subjectivity is incarnated and is in the life-world that has its own historical horizon.

This is a complex issue. Husserl himself posed the question: "Meanwhile, let us recapitulate once more that historical facts (as well as the present fact, that we exist) are only objective based on a priori. But does the a priori, in turn, presuppose history?" (HUSSERL, Anexo II to $\S 9$ a, 2008, p.367).

I believe that by posing this question, Husserl is being faithful to his thinking. Even though this was one of his final works, he still presented it as an introduction, still not at peace with the path travelled. His doubt: "Does historical a priori presuppose what is historical?" indicates the complexity in which we find ourselves while seeking to understand reality. ${ }^{34}$ Apparently, here the entirety of Husserl's philosophy faces a background problem. In order to explain that I resort to the words of David Kerr who translated Crisis from German to English. If all theoretical activity presupposes the structure of the life-world, then, he argues, this must also apply to phenomenology, which, in this case, could not be brought about without assumptions, one of its bases. Kerr arguments that Husserl needs to show that phenomenology can effectuate the telos of every theory without being "caught" in its "arché".

Was he being caught?

Residues of phenomenological reduction, the point of contention for his disciples and which became problematic for himself, no longer remain with the life-world. This issue arose because Husserl stated that nothing from reality was outside of this reduction. Now, reality can no longer be conceived as objectively given; a prevailing vision in modern positivism. It is a complexity that is present in the historical a priori that involves us all and, thus, the very questions about it. Putting it in suspension to understand it is a possible, laborious investigation. Nothing prevents transcendental phenomenology from putting it in epoché as it did geometry itself. Derrida (1994, p.117) criticized Husserl, as he did not fulfill what he promised: to know the thing itself always. I do not see it that way, as from the beginning of his work, Husserl made statements regarding the perception of the thing, not the thing itself. The motto go-to-the-thing-itself is related to what Derrida

\footnotetext{
${ }^{34}$ I wonder if he had continued his investigation, how would he view history as a Hegelian totality?
} 
himself said in the excerpt above: look at it and perceive it without intermediaries. The thing-in-itself is perceived, that is it. Point.

Through the historical a priori of the life-world we can understand the origin of geometry as historically investigable in the wake of its constitution and production, in the reality of the present instant.

\section{What was treated in the present article}

While conducting the work contained in this article, I understood that the concept of origin can point to one of the tips of the many threads through which one can begin to comprehend the meaning of Husserl's work. However, beyond this finding, the meaning that is evidenced is the origin regarding the principle of principles of phenomenology, as it maintains the understanding, including in The Origin of Geometry, that every originally offering vision must be accepted as it presents itself, but only within the limits in which it is presented. It persists in the concrete realization of its method, as stated by Ales Bello (2000, p.49), which is based on adherence to what is essentially, that is, originally presented.

Husserl was challenged by modern science in terms of understanding it; how it is constituted and produced. Initially, he focused on arithmetic and its foundation and, in a crescendo, encompassed mathematics, modern sciences and took geometry as exemplary to pace the guiding thread that can be pulled in the present, go backwards, aiming to clarify the way through which this science was constituted.

To do so, he considered, the origin of the idea in the subjective act of evidence that occurs in the now, and advanced, conducting rigorous investigations regarding the understanding of psychical acts; the hyletic dimension of experiences, as well as their intertwining in the unity of the living-body, in which consciousness itself moves in its fluid lightness, functioning as a source of meaning and a conductor of reflection; of the constitution of the sphere of intersubjectivity and objectivity, explaining entropathy and dedicating itself to language.

His investigation explicitly focused on knowledge. He stated that the reality of the external world is not viewed as a priority in its theme. He even separated it from what he wanted to investigate, in the movement of epoché. However, in my opinion, the issue of reality remains as intriguing residue. 
He became aware of that while experiencing the glaring crisis that took hold of Europe in the aftermath of World War I, about which he talked in 1922. He set out to investigate the origin of that crisis, with the rigor of phenomenological procedures, always seeking to understand it in the context of the basic underlying issues brought about by the vision of modern science that dominates the logic of the academics who assume it. Not only that, but also dominate the manner ordinary people act, involved in and by the reality of the life-world, given the practical applications of the theories of these sciences. He thematized the life-world. He understood it as a historical a priori that embraces us all, and transcends us all, constituting itself as a ground where we live individually with others, in our finitude, and collectively as mankind. A priori that precedes science, constituting its a priori. However, it is not an objectively given reality, simply external to the subject who gets to know it and who can know it objectively and accurately. It is rather a complex reality, which brings in itself the vivacity of the life of the world, thus Lebenswelt, and in the movement of being, the world. Therefore, the residues concerning reality that remain in the eidetic reduction, in the movement of epoché, are no longer left out, as this reality is also embodied in the living-body of each of us, individually and together, with our co-subjects, all present in the production and in life within the lifeworld.

Is it a closed system? I do not believe so. I see it as a horizon, open to understandings. I believe that Husserl was aware of this, and that is why, to the end of his days he referred to his work as introduction to phenomenology. He assumed his philosophical position: philosophy is to teach us how to carry out the eternal task of humanity. It must not only enlighten men about actual states of affairs, but also provide leadership in ethical and religious matters.

\section{References}

ALES BELLO, A. Husserl e le scienze. Roma: La Goliardica editrice universitária di Roma, 1986.

ALES BELLO, A. A fenomenologia do ser humano. Bauru: Edusc, 2000.

ALES BELLO, A. ...e la coscienza? Fenomenologia psico-patologia neuroscienze. Bari: Edizioni Giuseppe Laterza, 2012.

BICUDO, M. A. V. Sobre história e historicidade em Edmund Husserl. Cadernos da EMARF, Fenomenologia e Direito, Rio de Janeiro, v. 9, n.1, p.21-48, 2016. 
DE BOER, T. The Development of Husserl's Thought. Translated by Theodore Plantina. The Hague/Boston/London: Martinus Nijhoff, 1978.

DERRIDA, J. A voz e o Fenômeno. Rio de Janeiro: Jorge Zahar Editor, 1994.

HEIDEGGER, M. Discourse on Thinking. New York, Evanston e London: Harper \& Row, Publishers, 1962.

HUSSERL, E. Licões para uma fenomenologia da consciência interna do tempo. Coimbra: Estudos Gerais - série universitária, s/d.

HUSSERL, E. Logical Investigations (Logische Untersuchungen). Volumes 1 and 2. (International Library of Philosophy). New York and London: Routledge, 1970. Edition of Kindle.

HUSSERL, E. The Crises of European Sciences and transcendental Phenomenology. Traduzido por David Kerr. Evanston: Northwestern University Press, 1970.

HUSSERL, E. Ideas. General Introduction to Pure Phenomenology. London: CollierMacmillan Ltd., 1972 (fourth printing - First published to English, 1931).

HUSSERL, E. Cartesian Meditations - An introduction to phenomenology. Translated by Dorion Cairns. The Hague: Martinus Nijhoff, 1977.

HUSSERL, E. Idee per uma fenomenologia pura e per uma filosofia fenomenológica. Vol. II. Livro Secondo - Richerche fenomenologiche sopra la costituzione; Livro Terzo - La fenonomenologia e i fondamenti delle scienze. Traduzione di Enrico Philipo. Torino: Einaudi, 2002.

HUSSERL, E. Philosophy of Arithmetic. - Psychological and Logical Investigations with texts supplementary texts from 1887 - 1901. Traduzido por Dallas Willard Dordrecht: Springer Science+Business Media Dordrecht, 2003.

HUSSERL, E. Europa: crise e renovação. Tradução de Pedro M. S. Alves e Carlos Aurélio Morujão Artigos para a Revista Kaizo. Lisboa: Centro de Filosofia da Universidade de Lisboa, 2006.

HUSSERL, E. Anexo II ao § 9 $9^{\mathrm{a}}$. In: HUSSERL, E. A Crise das Ciências Europeias e a Fenomenologia Transcendental. Uma introdução à Filosofia Fenomenológica. Tradução de Diogo Falcão Ferrer. Lisboa: Phainomenon e Centro de Filosfia da Universidade de Lisboa, 2008. p. $369-395$.

HUSSERL, E. Anexo XXVI ao $§ 73$ Estádios da historicidade. Historicidade primeira. In: HUSSERL. E. A crise das Ciências Européias e a Fenomenologia Transcendental. Uma Introdução à Filosofia Fenomenológica. Traduação de Diogo Falcão Ferrer. Lisboa: Phainomenon e Centro de Filosfia da Universidade de Lisboa, 2008.p. 522 - 523.

PRADA, O. G. La fundamentación de la matemática y la génises de la métodica fenomenológico-reductiva. In: SEMINAIRIO DE HISTORIA DE LA FILOSOFIA, VI1986-87-88-89, Marid. Anales... Madrid: Ed. Univ.Complutense, 1986. p. 47- 78.

Received in: July 20, 2020.

Accepted on: August 22, 2020. 